\title{
PROPERTIES AND STRUCTURE OF CELLULOSIC MEMBRANES OBTAINED FROM SOLUTIONS IN IONIC LIQUIDS COAGULATED IN PRIMARY ALCOHOLS
}

\author{
Beata Fryczkowska*1, Małgorzata Kowalska², Dorota Biniaś1, Czesław Ślusarczyk', \\ Jarosław Janicki ${ }^{1}$, Ewa Sarna1 ${ }^{1}$, Mirosław Wyszomirski ${ }^{1}$
}

\begin{abstract}
${ }^{1}$ University of Bielsko-Biala, Faculty of Materials, Civil and Environmental Engineering, Institute of Textile Engineering and Polymer Materials, Willowa 2, 43-309 Bielsko-Biala, Poland, tel. +48 338279114; fax: +48 338279100; email: *bfryczkowska@ath.bielsko.pl (B. Fryczkowska) ${ }^{2}$ Silesian University of Technology, Faculty of Power and Environmental Engineering, Institute of Water and Wastewater Engineering, Konarskiego 18, 44-100 Gliwice, Poland
\end{abstract}

\begin{abstract}
:
This paper presents the results of studies on the preparation of cellulosic membranes, from a solution in 1-ethyl-3methylimidazolium acetate (EMIMAc), using the phase inversion method. Initially, the membranes were obtained by coagulation of the polymer film in water and primary alcohols (methanol, ethanol, 1-propanol, 1-butanol, 1-pentanol), 1-hexanol, 1-octanol) resulting in membranes with significantly differing morphologies. Subsequently, composite membranes were produced, with the support layer being a membrane with the largest pores, and the skin layer a membrane with smaller pores. The resulting membranes were tested for physicochemical and transport properties. The morphology of the membrane surfaces and their cross-sections were investigated by using a scanning electron microscope (SEM). The structure of the membranes, on the other hand, was investigated by FTIR spectroscopy and WAXS structural analysis.
\end{abstract}

\section{Keywords:}

cellulose, ionic liquid, membranes, transport properties, morphological structure

\section{Introduction}

Among all natural organic compounds, cellulose is seen as the most widespread, inexpensive, biodegradable polymer derived from renewable sources [1]. Both cellulose and its derivatives are used on a large scale in the form of paper, films, fibers, textiles and membranes [2,3]. As cellulose finds applications in a wide area, it is a material of great industrial importance.

Cellulose is a linear polymer formed by a linkage of stable glycosidic bonds, which are interspersed with intra- and intermolecular hydrogen bonds. The presence of these bonds, as well as the presence of crystalline areas in cellulose, makes this polymer insoluble in water and in most organic solvents $[2,4,5]$. Therefore, many systems capable of dissolving this polymer have been developed, including $\mathrm{NaOH} / \mathrm{CS}_{2}$, DMSO/TBAF, LiCl/DMAc, and $\mathrm{N}_{2} \mathrm{O}_{4}$ /DMF [6,7], which have disadvantages such as volatility, toxicity, or flammability. Another system used to dissolve cellulose is $\mathrm{NMMO} / \mathrm{H}_{2} \mathrm{O}$, which, unlike previously mentioned ones, is environmentally friendly and cost-effective [6].

An interesting group of compounds are ionic liquids (ILs) used to dissolve, under mild conditions, very hardly soluble materials such as cellulose [8]. They are called direct cellulose solvents and form an environmentally friendly and biodegradable solvent systems [5]. Chemically, ionic liquids are made of an organic cation and smaller, organic or inorganic anion [5], and the most interesting are the properties of room temperature ionic liquids (RTILs) [9]. The ability to dissolve cellulose in ionic liquids allows for a relatively simple processing of this polymer to obtain fibers [10-16], nanofibers [17-19] cellulose particles [20], cellulose gels and aerogels [21-24], flocs [25] and membranes.

Swatloski et al. [26] were the first to describe the dissolution of cellulose in 1-butyl-3-methyl imidazolium chloride. They reported that the chemical structure of the imidazole cation in the ionic liquid has a strong influence on the viscosity of the obtained polymer solutions [26]. Kosan et al. [17] investigated the properties of various ionic liquids, but the most interesting turned out to be 1-butyl-3-methyl imidazolium acetate, using which a $13.5 \%$ cellulose solution can be prepared. This liquid possesses more advantages, such as low melting point, high boiling point and good thermal stability [27]. Ding et al. [25] used EMIMAc to dissolve microcrystalline cellulose, thus obtaining a $5 \%$ solution. Whereas Mahadeva et al. [28] used a $2 \%$ solution of cellulose for membrane molding, the coagulation was carried out in water, methanol, a mixture of methanol with water (30:70) and isopropyl alcohol. Sun et al. [29] reported that the $5 \%$ solution of cellulose in EMIMAc was coagulated in acetone/water mixture (1: $1 \mathrm{v} / \mathrm{v})$. Hermanutz et al. [10] used 10, 12 and $16 \%$ cellulose solutions in EMIMAc to produce cellulose fibers by coagulation in water. Livazovic et al. [30] described the preparation of cellulose solutions at various concentrations: $2.0,5.0$ and $10 \%$ of cellulose in 1-ethyl3-methylimidazolium acetate by heating it at $80^{\circ} \mathrm{C}$ for $24 \mathrm{~h}$. The solutions thus obtained were molded with a casting knife with an adjustable thickness fixed at $0.15 \mathrm{~mm}$, and the resulting films were coagulated in distilled water. 
Literature provides many examples of the preparation of cellulose-containing composite membranes. Li et al. [31] obtained composite membranes by pouring the solution of cellulose in ionic liquid onto a PET nanofiber mat. Turner et al. [32] described the preparation of cellulose-polyamine composite by dissolving both components in 1-butyl-3methylimidazolium chloride, followed by their coagulation in water.

This paper presents research on the production of cellulosic membranes by classical wet phase inversion method. 1-Ethyl3-methylimidazolium acetate (EMIMAc) was selected as the solvent, since it is, according to Gupta et al. [33], an ionic liquid that breaks the hydrogen bonds in cellulose most easily (Fig. 1), as also confirmed by studies of Sun et al. [29]. A 5\% cellulose solution in EMIMAc was prepared, as reported by Livazovic et al. [30]. Dissolution of cellulose was carried out using the microwave method [34], by pulse heating of the solution $[7,26]$. The cellulose dissolved in ionic liquids can be coagulated in polar solvents [35]. In our experiment, water (W) [24,25,28,30] and primary alcohols differing in polarity such as methanol [28,36], ethanol [24,36], 1-propanol [28], 1-butanol, 1-hexanol and 1-octanol were used for the coagulation of cellulosic membranes. This paper describes the study of the impact of coagulant and drying process on physicochemical, transport and structural properties as well as surface morphology of cellulose membranes.

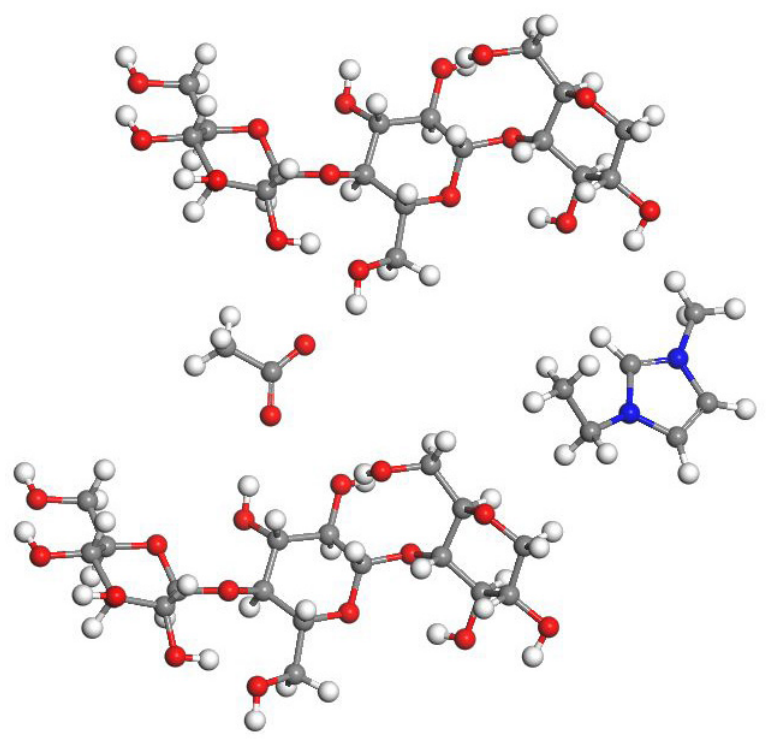

Figure 1. Diagram of a solution containing a short fragment of cellulose (cellotriose) in EMIMAc

\section{Experimental}

\subsection{Materials}

Cellulose (long fibers; C 6663), 1-ethyl-3-methylimidazolium acetate (EMIMAc) with $97 \%$ (w/w) purity, 1-octanol (O, 99\%) were purchased from Sigma-Aldrich. Methanol (M, 99.8\%), ethanol ( $E, 96 \%)$, 1-propanol (P, 99.5\%), 1-butanol (Bu, 99.5\%), 1-pentanol $(\mathrm{Pe}, 98.5 \%)$ and 1-hexanol $(\mathrm{H}, 98 \%)$ were purchased from Avantor Performance Materials Poland S.A. All the chemicals were used without further purification.

\subsection{Preparation of cellulose solution}

Initially, a $5 \%$ solution of cellulose in the ionic liquid, 1-ethyl3-methylimidazolium acetate, (EMIMAc) was prepared. For this purpose, adequate amounts of cellulose and ionic liquid were combined to obtain solutions with concentrations of 2.5; $5.0 ; 7.5$ and $10 \%$ by weight (Table 1 ). The whole solution was then mixed thoroughly, then heated in a laboratory microwave oven at three intervals of $5 \mathrm{~s}$, keeping the temperature of the mixture below approx. $40^{\circ} \mathrm{C}$. It was observed that a very accurate mixing at the intervals between heating prevents local overheating of cellulose and its degradation [34]. The obtained cellulose solutions were allowed to deaerate for $24 \mathrm{~h}$. The viscosity of the prepared cellulose solutions was measured at room temperature by means of Myr V2-L rotary viscosity gauge, equipped with L3 spindle and temperature sensor (Fig. 2).

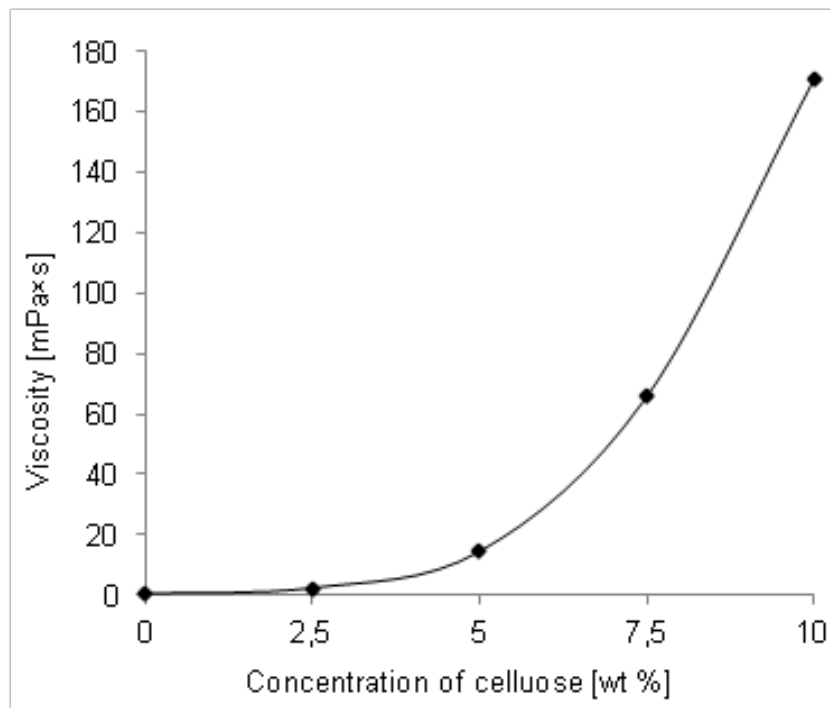

Figure 2. The results of viscosity tests of cellulose solutions in EMIMAc (measurement temperature. $25^{\circ} \mathrm{C}$ )

Looking at Fig. 2, we can see that the viscosity of the obtained cellulose solutions in EMIMAc increases drastically with its concentration. Above $10 \%$ wt. concentration, the cellulose solution forms a gel that prevents further dissolution of cellulose. As a result, $5 \%$ cellulose solution was selected for further investigation. A solution of this concentration was also used by Ding et al. for their research [25].

\subsection{Forming cellulose membranes}

Cellulose membranes were prepared using the phase inversion method. For this purpose, a $5 \%$ cellulose solution in EMIMAc was poured onto a level, clean glass plate. Then a polymeric film was formed using a casting knife with an adjustable thickness fixed at $0.2 \mathrm{~mm}$. After that, the plate and the cellulose solution distributed over it were transferred to a coagulant bath at room temperature and kept in it until the membrane peeled off the glass. The following solvents were used in coagulation solutions: distilled water $(W)$, methanol $(M)$, ethanol $(E)$, 1-propanol $(\mathrm{P})$, 1-butanol $(\mathrm{B})$, 1-pentanol $(\mathrm{Pe})$, 1-hexanol $(\mathrm{H})$ 
and 1-octanol (O). Cellulose membranes in the presence of water coagulate rapidly (10-30 $\mathrm{min}$ ) and are followed by ones immersed in alcohols containing 1 to 4 atoms of carbon in their molecule. Coagulation of cellulose solution in higher alcohols is very slow and it took 1 day (1-pentanol), 4 days (1-hexanol) and 5 days (1-octanol) for a membrane to separate from the glass plate, which indicated finalization of the process. After its completion, the membranes $\mathrm{Pe}, \mathrm{H}$, and $\mathrm{O}$ were repeatedly rinsed, alternately with distilled water and methanol, until the characteristic odor of the alcohol disappeared, and then air dried. In our laboratory, a thin layer of polyester fabric followed by layers of tissue paper were used to separate the cellulose membranes. This prevents sticking of the cellulose to the filter paper and facilitates drying. Finally, the dried membranes were loaded in a glass plate to prevent membrane ripple.

\subsection{Characterization techniques}

The cellulose membranes obtained in the experiments were characterized using FTIR spectroscopy with diffusion accessory, X-ray scattering (WAXS) and scanning electron microscopy (SEM).

Wide-angle X-ray scattering (WAXS) investigations were carried out with a URD-65 Seifert diffractometer. $\mathrm{CuK}_{\alpha}$ radiation was used at $40 \mathrm{kV}$ and $30 \mathrm{~mA}$. Monochromatization of the beam was obtained by using a nickel filter and a graphite crystal monochromator placed in the diffracted beam path. A scintillation counter was used as a detector. Investigations were performed in the range of the angle $3^{\circ}$ to $40^{\circ}$ in steps of $0.1^{\circ}$.

Nicolet 6700 Fourier transform spectrophotometer (Thermo Scientific, USA) with OMNIC 7.0 software and EasiDiff diffusion accessory (Thermo Nicolet Industries) was used in the FTIR spectroscopic analysis. The spectral region was as follows: 4000-500 $\mathrm{cm}^{-1}$, resolution: $4 \mathrm{~cm}^{-1}$, number of scans: 64 of the solid samples. In the course of the examination, the spectra of three repacked subsamples of each individual sample were averaged to one spectrum. Each spectrum was performed with the use of a linear baseline and preprocessed by means of Fourier smoothing.

Observations of the membranes surface morphology and their cross-sections were carried out using JSM-5500 LV JEOL scanning electron microscope. All samples were coated with a layer of gold in JEOL JFC 1200 vacuum coater at $3 \times 10^{-5} \mathrm{Tr}$.

Studies of permeate containing $\mathrm{FeCl}_{3}$ solution were performed with Perkin Elmer Lambda 35 UV-vis spectrophotometer at a wavelength of $260 \mathrm{~nm}$.

\subsection{General characterization}

Thickness (I) of the membranes was measured with ELMETRON MG-1 thickness gauge. Samples with dimensions of $1 \times 1 \mathrm{~cm}$ were weighed using SARTORIUS CP224S-0CE analytical balance with an accuracy of $0.0001 \mathrm{~g}$. The apparent density $(\mathrm{dm})$ of the membranes $\left(\mathrm{g} / \mathrm{cm}^{3}\right)$ was calculated using the following formula (1):

$$
d_{m}=\frac{w}{s \times l}
$$

where $w$ is the mass of a membrane with an area of $1 \mathrm{~cm}^{2}, s$ is the membrane surface area $\left(\mathrm{cm}^{2}\right)$, and $I$ is the membrane thickness $(\mathrm{cm})$.

Since cellulose is a highly hydrophilic material, the sorption properties $(U)$ of the membranes were tested using benzene. Samples of membranes with dimensions of $1 \times 1 \mathrm{~cm}$ were weighed on an analytical balance with an accuracy of 0.0001 $\mathrm{g}$, and then inserted into benzene for $3 \mathrm{~min}$ (dried over $3 \AA$ molecular sieves). Then they were blotted on filter paper and weighed again in the wet state. The sorption properties (U) were calculated using the following formula (2):

$$
U=\frac{W_{w}-W_{d}}{W_{d}} \times 100 \%
$$

Porosity of the membranes $(\varepsilon)$, which is defined as the ratio of pore volume to the volume of the membrane, was calculated using the following formula [37] (3):

$$
\varepsilon=\frac{\left(W_{w}-W_{d}\right) / \mathrm{dw}}{\left(W_{w}-W_{d}\right) / d_{w}+W_{d} / d_{p}} \times 100 \%
$$

where: $w w$ is the wet sample weight $(\mathrm{g})$; $w d$ the dry sample weight $(\mathrm{g})$; $d w$ the density of benzene $\left(0.875 \mathrm{~g} / \mathrm{cm}^{3}\right) ; d p$ the polymer density $\left(1.55 \mathrm{~g} / \mathrm{cm}^{3}\right)$ [38].

\subsection{Transport properties}

Transport properties of the obtained membranes were tested using a Millipore's Amicon 8400 ultrafiltration cell with a capacity of $350 \mathrm{~cm}^{3}$ and a membrane diameter of $7.6 \mathrm{~cm}$, equipped with equalizing tank with a capacity of $800 \mathrm{~cm}^{3}$. Initially, the membranes were immersed in distilled water for $1 \mathrm{~h}$ and then treated with distilled water for $2 \mathrm{~h}$ at $0.2 \mathrm{MPa}$ (which has a positive effect on the membrane stability). Tests were then carried out at a working pressure of $0.1,0.15$ and $0.2 \mathrm{MPa}$. Permeate flux (JV) was calculated using the following formula (4):

$$
J_{v}=\frac{Q}{A \times t}
$$

where $J v$ is the water flux $\left(\mathrm{L} / \mathrm{m}^{2} \times \mathrm{h}\right), Q$ is the permeate volume $(L), A$ is the effective membrane area $\left(m^{2}\right)$, and $t$ is the permeation time $(h)$.

Pore size $(\mathrm{rm})$ was calculated on the basis of specific permeate flux and porosity using Guerout-Elford-Ferry equation [37] (5)

$$
r_{m}=\sqrt{\frac{(2.9-1.75 \varepsilon) 8 \eta l Q}{\varepsilon \times A \times \Delta P}}
$$

where $\eta$ is the water viscosity $\left(8.9 \times 10^{-4}[\mathrm{~Pa} \cdot \mathrm{s}]\right), I$ is the membrane thickness $(\mathrm{m}), Q$ is the volume of permeated pure water per unit time $\left(\mathrm{m}^{3} / \mathrm{s}\right), A$ is the effective membrane area $\left(\mathrm{m}^{2}\right)$ and $\Delta P$ is the operational pressure.

Additionally, membrane separation properties studies were also conducted using an aqueous solution of $\mathrm{FeCl}_{3}$ at a concentration of $0.1 \mathrm{~g} / \mathrm{dm}^{3}$. To this end, the solution of iron ions 
was added to the ultrafiltration cell with a previously tested membrane. In addition, a mixing element (magnetic bar) was also added to the ultrafiltration cell and the set was placed on a magnetic stirrer. The permeation process was carried out at a pressure of $0.2 \mathrm{MPa}$, drawing permeate every $5 \mathrm{~min}$ and measuring its volume. Permeate flux $(J p)$ was calculated using formula (4), assuming that in this case $Q$ is the permeate volume $\left(\mathrm{FeCl}_{3}\right.$ solution) per unit time $\left[\mathrm{m}^{3} / \mathrm{s}\right]$.

The concentration of $\mathrm{FeCl}_{3}$ solution in the permeate was determined by using UV-Vis spectrophotometer and measuring the absorbance at a wavelength of $260 \mathrm{~nm}$. Based on the calibration curve, the concentrations of ferric ions in each sample were calculated. Then, the following formula (6) was used to calculate to rejection performance $(R)$ for $\mathrm{FeCl}_{3}$.

$$
R=\left(1-\frac{C_{p}}{C_{f}}\right) \times 100 \%
$$

where $R$ is the rejection performance of the membrane (\%) and $\mathrm{Cp}$ and $\mathrm{Cf}$ are the concentrations of $\mathrm{FeCl}_{3}$ in the permeate and feed solution $(g / L)$, respectively.

\section{Results and discussion}

\subsection{WAXS analysis}

Cellulose is a partially crystalline polymer characterized by a polymorphism of crystallites. Typically cellulose has four types of crystal structures, namely cellulose I, II, III and IV, all of which can transform from one type to another [28,39-41]. Figure 3 shows the WAXS diffraction pattern of native cellulose used in the preparation of membranes. It exhibits a typical cellulose I structure indicated by the diffraction peaks at $2 \theta=14.8^{\circ}, 16.3^{\circ}$, $22.5^{\circ}$ and $34.3^{\circ}$ assigned to $(-110),(110),(200)$ and $(300)$ planes, respectively.

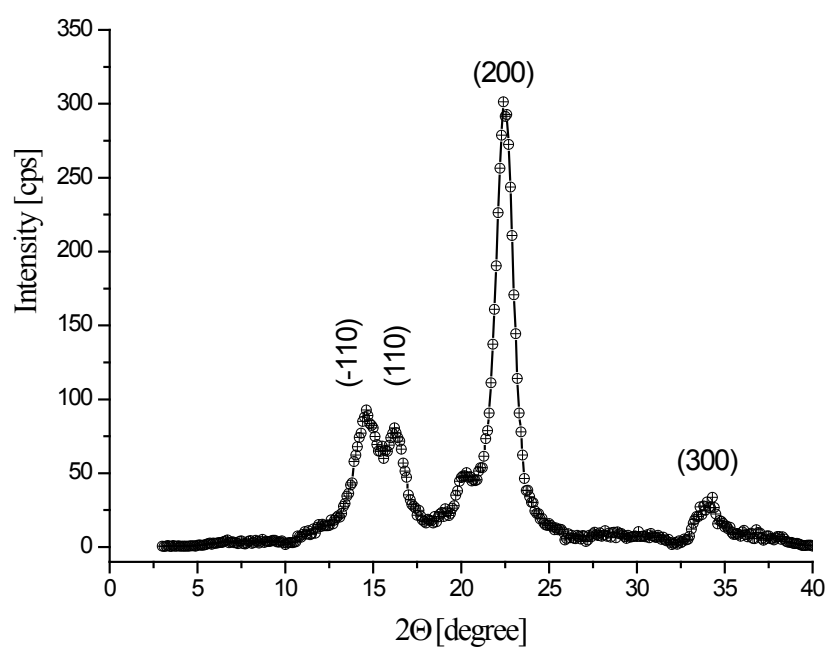

Figure 3. WAXS pattern of native cellulose

Observing Figure 4, it shows that after dissolution and subsequent coagulation with primary alcohols, the regenerated cellulose exhibits the typical diffraction patterns of cellulose II crystalline structure as revealed by the characteristic peak at $2 \theta=12.6^{\circ}(-110)$ and close to each other two peaks at $2 \theta$ $=20.3^{\circ}(110)$ and $21.2^{\circ}(-121)$. The obtained results indicate that the transformation from cellulose I to cellulose II occurred after the dissolution and regeneration in primary alcohols. This phenomenon is consistent with that reported in most other known solvent systems for cellulose. Compared to the native cellulose, the intensity of diffraction peaks of these regenerated cellulose membranes are reduced significantly. This means that the crystallinity of these membranes was lower than that of the original cellulose.

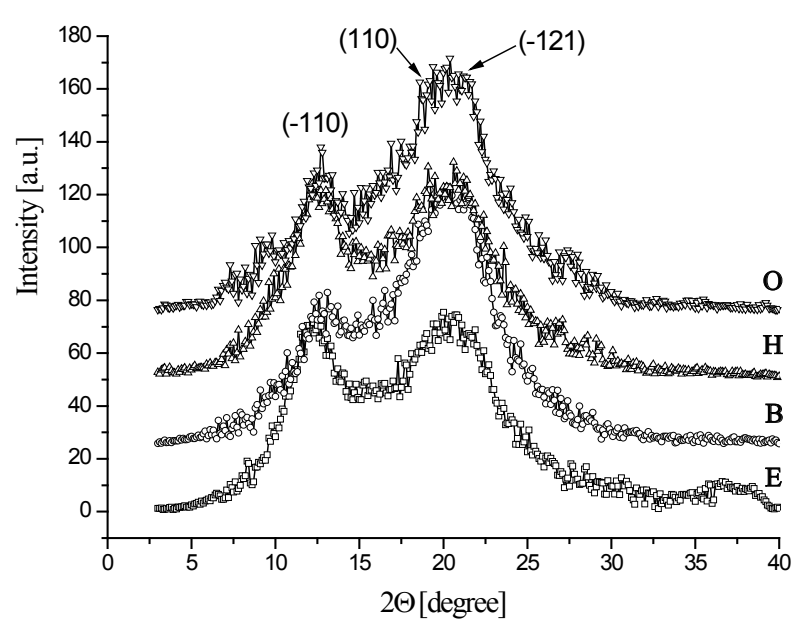

Figure 4. Examples of WAXS patterns of cellulose membranes regenerated from primary alcohols (E - ethanol; $B$ - 1-butanol; $\mathrm{H}-$ 1-hexanol; O - 1-octanol)

To quantitatively examine the crystallinity of the membranes studied, their crystallinity index was evaluated from WAXS measurements. For this purpose each WAXS curve was deconvoluted into crystalline and amorphous scattering components using the profile-fitting program WaxsFit [42]. Each peak was modeled using a Gaussian-Cauchy peak shape. The crystallinity index was calculated as a ratio of the area under crystalline peaks to the total area of the scattering curve. The calculated crystallinity index of native cellulose was found to be 0.756 , whereas for the membranes the value of this parameter ranged from 0.31 to 0.45 and was significantly affected by the type of the coagulant.

In our previous paper [43], the pore dimensions and the pore volume fraction of these cellulose membranes were estimated by means of small-angle X-ray scattering (SAXS) method. It was found that both content and dimensions of pores depend on molecular mass of the coagulant used. Also, it was found that the dipole moment of coagulant molecules has a large influence on the volume content of the pores. The WAXS results presented here show another interesting correlation. Figure 5 shows the dependence of the crystallinity of the membranes on the pore content of these membranes and shows that the crystallinity index decreases, almost linearly, with increasing the volume fraction of pores. This result reflects the complexity of the process of membrane formation at the molecular level. The ionic liquid used to dissolve cellulose broke intermolecular and intramolecular hydrogen bonds and destroyed primary 
crystalline structure. The process of removing the solvent molecules by the coagulant molecules, resulting in recovery of the crystalline structure of cellulose, leads also to the formation of its porous structure. The obtained results indicate that the formation of pores to some extent hinders the process of crystallization of regenerated cellulose.

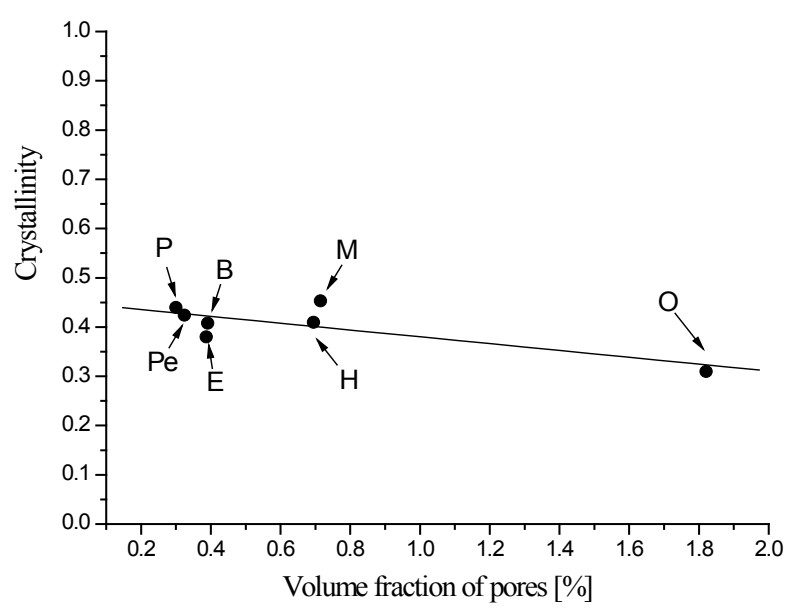

Figure 5. Effect of the volume fraction of pores on the crystallinity of membranes (M - methanol; E - ethanol; $\mathrm{P}$ - 1-propanol; B - 1-butanol; $\mathrm{Pe}$ - 1-pentanol; $\mathrm{H}$ - 1-hexanol; O - 1-octanol)

\subsection{FTIR analysis}

The chemical structure of cellulose membranes was investigated using FTIR spectroscopy (Fig. 6). The spectral characteristics of the absorption band for the $1430 \mathrm{~cm}^{-1}$ wave number responsible for the bending vibrations of the $\mathrm{CH}_{2}$ oscillators were observed. This band appears both in the starting cellulose spectrum as well as in all spectra of cellulose membranes regenerated in various solvents. A difference in intensity of this band $\sim 1430 \mathrm{~cm}^{-1}$ from the highest absorbance for pure cellulose is observed in the successive membranes: $\mathrm{W}, \mathrm{B}, \mathrm{E}, \mathrm{H}, \mathrm{Pe}, \mathrm{P}, \mathrm{M}, \mathrm{O}$. The absorbance drop for this peak may be due to the lack of reconstruction of intermolecular hydrogen bonds, which are formed by the primary hydroxyl group of C6 carbon at the glucopyranose ring $[28,44]$. As a result, differences in the forces of intermolecular interactions influence the blurring of the wave numbers for this oscillator and thus the relative intensity reduction. The characteristic wide band of the $\mathrm{O}-\mathrm{H}$ oscillator vibrations responsible for the formation of hydrogen bonds are observed at $3000-3700 \mathrm{~cm}^{-1}$. For the IR spectra of the membranes (pure cellulose and membrane $O$ ), the peak of the band is observed at $3415 \mathrm{~cm}^{-1}$ as well as its displacement toward the higher wave numbers successively for membranes: $\mathrm{H}, \mathrm{Pe}, \mathrm{B}, \mathrm{P}, \mathrm{E}, \mathrm{M}$ and $\mathrm{W}$ (for wave number of $\sim 3490 \mathrm{~cm}^{-1}$ ) [28,44]. The band at approximately $900 \mathrm{~cm}^{-1}$ is attributed to the effect of $\mathrm{C}-\mathrm{O}$ stretching vibrations in the amorphous areas of cellulose $[44,45]$ and its intensity is higher in cellulose membrane spectra due to which the blurring of $1430 \mathrm{~cm}^{-1}$ band is observed. This confirms a more amorphous structure of regenerated cellulose in these cases. Within the range of $1060-1160 \mathrm{~cm}^{-1}$, there are bands of $\mathrm{C}-\mathrm{O}-\mathrm{C}$ stretching vibrations that occur in both the glucopyranose ring and the glycosidic bridges. The fundamental difference between the shape of the bands in these areas for the initial cellulose, as compared to regenerated cellulose, indicates significant changes in the conformation of the cellulose chains, and hence the influence on the structure [45]. The occurrence of these bands may indicate that the macromolecular structure of cellulose changed during regeneration.

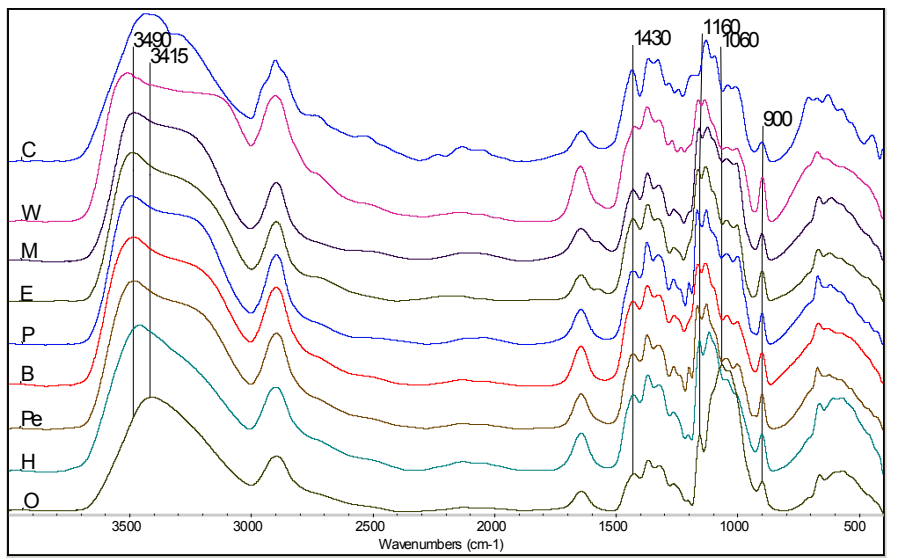

Figure 6. FTIR spectra of cellulose membranes (W, M, E, P, B, Pe, H, $\mathrm{O})$ and the initial long-fibers cellulose (C)

\subsection{SEM analysis}

Scanning electron microscopy enabled the observation of the surface morphology of skin layer, the support layer and crosssections of the obtained cellulose membranes (Fig. 7). SEM images of membranes W, E and P (Fig. 7-1) show cellulose layers arranged in parallel, similarly as reported in Ref. [46]. On the images of cross-sections of membranes, M, B and Pe, on the other hand, a compact structure with minor inclusions can be seen. The cross-section of the membrane $\mathrm{H}$, with large, symmetrically arranged closed chambers, is diametrically different from the other ones. Whereas the SEM image of the membrane $O$ cross-section can be distinguished by a thin skin layer, which is based on large, open, asymmetrical chambers of the support layer. In the photographs of membranes $\mathrm{W}, \mathrm{M}$ and $E$, the surface of the skin layer (Fig. 7-2) is smooth, while membrane $P$ is rough and covered with inclusions. The pictures of membranes $\mathrm{B}, \mathrm{Pe}, \mathrm{H}$ and $\mathrm{O}$ reveal a very rich skin layer surface, which changes from large, flat to finer and deeper hollows. Surface of the support layers of all membranes (Fig. 7-3) is richer in various morphological elements as compared to the skin layer. In the case of membrane $\mathrm{O}$, large multilayer chambers with walls covered with micropores can be observed.

\subsection{Characterization of the cellulose membranes}

On studying the physicochemical properties of the obtained cellulose membranes, it was observed that they depend on the type of coagulant used (Table 1). Membrane M, coagulated in methanol, had the highest density $\left(1.1033 \mathrm{~g} / \mathrm{cm}^{3}\right)$ and the lowest thickness $(\sim 13 \mu \mathrm{m})$. Comparing the obtained result with the pure cellulose density of $1.55 \mathrm{~g} / \mathrm{cm}^{3}$ [38], it can be concluded that the membrane $\mathrm{M}$ has a compact structure, as also evidenced by its porosity $(60.31 \%)$. The results confirm the study of sorption properties, which shows that the membrane $\mathrm{M}$ is characterized by very low sorption $(0.98 \%)$. A high density of $0.9 \mathrm{~g} / \mathrm{cm}^{3}$ was also characteristic of the membrane $(\mathrm{Pe})$, 

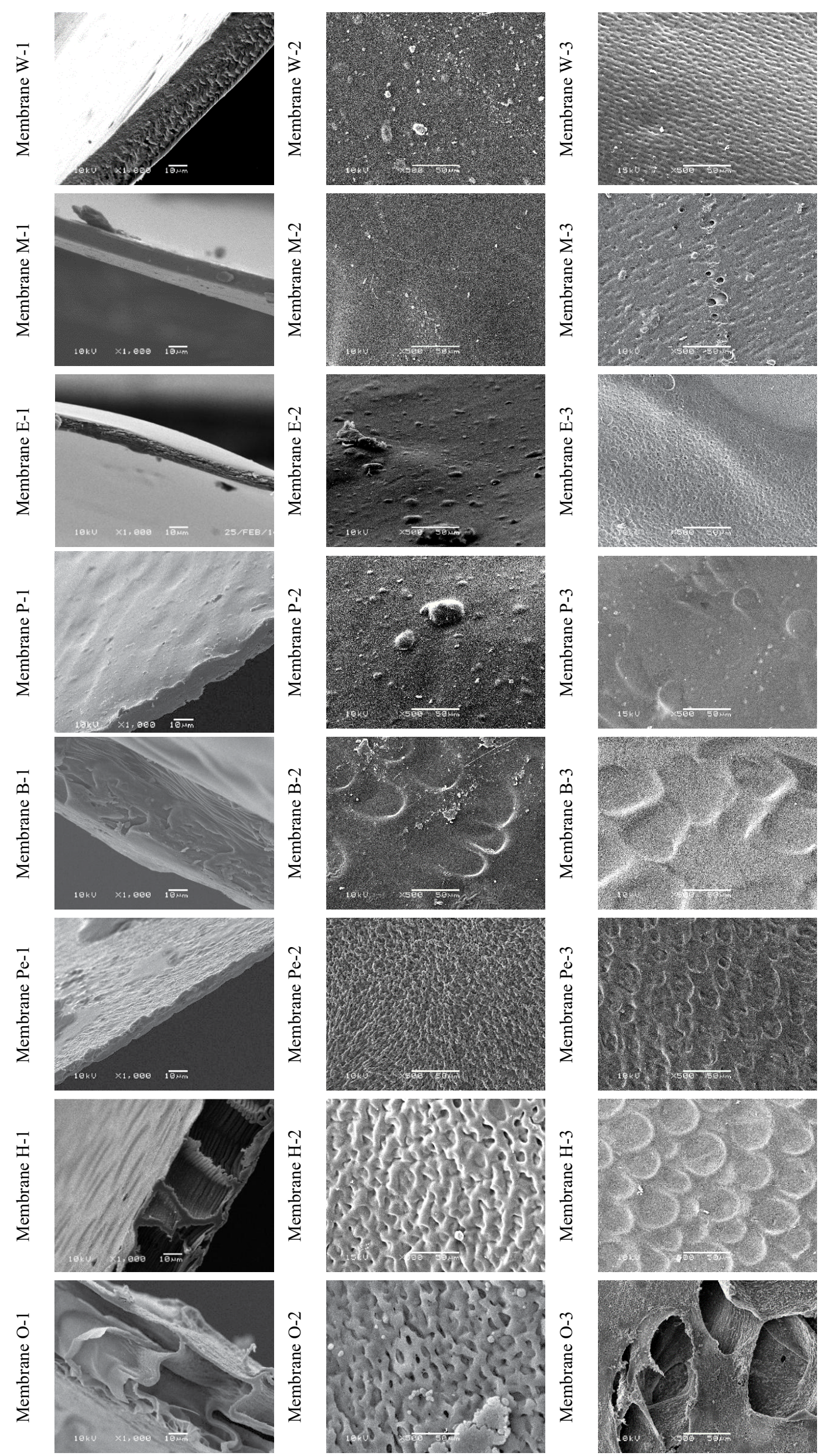

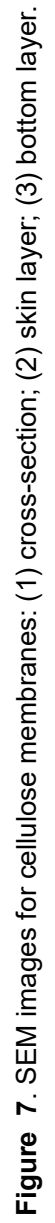


coagulated in 1-pentanol, which featured a low thickness $(15 \mu \mathrm{m})$ and a low sorption of $4.44 \%$. The results show that methanol and 1-pentanol are coagulants, which flush the ionic liquid from the cellulose solution, resulting in relatively high density and low thickness membranes, which in turn leads to a compact membrane structure that prevents sorption of the solvent (benzene).

Cellulosic membranes $\mathrm{E}$ and $\mathrm{P}$, on the other hand, have similar physicochemical properties with values ranging between the ones for membrane $\mathrm{M}$ and membrane $\mathrm{H}$. Membrane $\mathrm{E}$ has a thickness of $16.6 \mu \mathrm{m}$, density of $0.63 \mathrm{~g} / \mathrm{cm}^{3}$ and low sorption of $4.2 \%$, whereas the membrane $\mathrm{P}$ has values slightly higher than the previous one: thickness of $18.2 \mu \mathrm{m}$, density of $0.69 \mathrm{~g} / \mathrm{cm}^{3}$ and sorption at $6.22 \%$.

Higher alcohols such as 1-hexanol and 1-octanol impact cellulose coagulation process in a significantly different way. The membranes formed under their influence are characterized by a high thickness of $45 \mu \mathrm{m}$ (membrane O) and $41 \mu \mathrm{m}$ (membrane $\mathrm{H}$ ) and by a low density of 0.3983 and $0.38 \mathrm{~g} / \mathrm{cm}^{3}$, respectively. These properties affect membrane sorption, which is as high as $305 \%$ (O membrane) and $392 \%$ (membrane $\mathrm{H}$ ), respectively. These studies show that both 1-hexanol and 1-octanol elute the ionic liquid from the cellulose solution very slowly, which results in the formation of membranes made up of structures with high porosity of $99.8 \%$.

The properties of membrane B differ from the others. The membrane coagulated in 1-butanol is characterized by a high thickness of $40.09 \mu \mathrm{m}$, which is similar to membranes $\mathrm{H}$ and $\mathrm{O}$. Membrane $\mathrm{B}$ has a similar density as membranes $\mathrm{E}$ and $\mathrm{P}$, reaching $0.9 \mathrm{~g} / \mathrm{cm}^{3}$. However, the sorption properties are low $(22.6 \%)$, with a porosity of $97 \%$. This result may indicate that membrane $B$ is composed of closed pores. A water-coagulated cellulose membrane may have a similar structure, which has a thickness of $27 \mu \mathrm{m}$, at a low density of $0.4717 \mathrm{~g} / \mathrm{cm}^{3}$, low sorption (18.9\%) and a high porosity of $96.7 \%$.

\subsection{Transport properties and pore sizes of membranes}

The important parameters determining the properties of the membranes are the volumetric permeate flux (Fig. 8) and pore size (Fig. 9). The cellulose membranes obtained as

Table 1. Physical and chemical properties of cellulose membranes

\begin{tabular}{|c|c|c|c|c|c|}
\hline \multicolumn{2}{|c|}{ Membrane } & I $[\boldsymbol{\mu m}]$ & $\mathbf{d m}[\mathbf{g} / \mathbf{c m}]$ & U [\%] & $\boldsymbol{\varepsilon}[\%]$ \\
\hline water & $\mathbf{W}$ & $27.44 \pm 2.05$ & $0.4717 \pm 0.0390$ & $18.92 \pm 1.52$ & $96.70 \pm 7.26$ \\
\hline methanol & $\mathbf{M}$ & $12.74 \pm 0.99$ & $1.1033 \pm 0.0992$ & $0.98 \pm 0.11$ & $60.31 \pm 4.76$ \\
\hline ethanol & $\mathbf{E}$ & $16.58 \pm 0.95$ & $0.6299 \pm 0.0451$ & $4.20 \pm 0.22$ & $86.69 \pm 5.52$ \\
\hline 1-propanol & P & $18.20 \pm 0.98$ & $0.6868 \pm 0.0614$ & $6.22 \pm 0.34$ & $90.61 \pm 7.93$ \\
\hline 1-butanol & B & $40.09 \pm 2.11$ & $0.6174 \pm 0.0432$ & $22.59 \pm 1.74$ & $97.22 \pm 6.99$ \\
\hline 1-pentanol & Pe & $15.04 \pm 0.90$ & $0.9004 \pm 0.0695$ & $4.44 \pm 0.29$ & $87.32 \pm 5.11$ \\
\hline 1-hexanol & H & $41.18 \pm 3.54$ & $0.3800 \pm 0.0128$ & $392.33 \pm 6.78$ & $99.84 \pm 9.01$ \\
\hline 1-octanol & O & $44.86 \pm 2.78$ & $0.3983 \pm 0.0143$ & $304.48 \pm 6.32$ & $99.79 \pm 7.98$ \\
\hline
\end{tabular}

a result of the experiment differed in terms of their transport properties depending on the coagulant used. The lowest values of volumetric permeate flux, recorded for the membrane $\mathrm{W}$, for the subsequent pressures of $0.1,0.15$ and $0.2 \mathrm{MPa}$, were respectively $3.33 \pm 0.12,3.87 \pm 0.13$ and $5.24 \pm 0.39$ $\mathrm{L} / \mathrm{m}^{2} \times \mathrm{h}$. A slow but a slight increase in the permeate flux, which is observed with the increase of working pressure, may indicate a compact structure of membrane $\mathrm{W}$. It can therefore be assumed that membrane $W$ is composed of closed pores. The obtained results are confirmed in the physicochemical properties described above, such as low density and sorption, as well as by SEM images (Fig. 7), whereas the calculations show that the membrane $\mathrm{W}$ has pores with sizes of $1.50 \pm$ $0.03 \mathrm{~nm}$. This result is in the range of $0.614-2.254 \mathrm{~nm}$, and the calculations were based on SAXS diffraction curves, and presented in our previous publication [43].

The transport properties of cellulose membranes E, P and $\mathrm{Pe}$ are similar. The permeate flux for these membranes increases slowly with the increase in working pressure and for 0.2 MPa Their values are $9.27 \pm 0.55$ (membrane E), 9.27 \pm 0.37 (membrane P), $7.95 \pm 0.25$ (membrane $\mathrm{Pe}$ ) L/m² $\times \mathrm{h}$, respectively. The pore size calculated for membrane $E$ is $1.53 \pm$ $0.01 \mathrm{~nm}$, which is within the specified [43] range of 0.578-2.296 $\mathrm{nm}$. On the other hand, for the membrane $\mathrm{P}$, the pore size is $1.66 \pm 0.01 \mathrm{~nm}$, which is consistent with the boundary values, 0.55-2.498 nm, calculated based on the SAXS scattering curves [43]. The results of the pore size calculation for cellulose membrane coagulated in 1-pentanol showed that the pore size is $1.22 \pm 0.01 \mathrm{~nm}$, which is also consistent with our previous calculations [43].

The volumetric permeate flux of membrane $B$ for working pressures of $0.1,0.15$ and $0.2 \mathrm{MPa}$ is $4.89 \pm 0.49 ; 10.19 \pm 0$. $52 ; 14.17 \pm 0.63 \mathrm{~L} / \mathrm{m}^{2} \times \mathrm{h}$, respectively. Thus, as the working pressure rises, the permeate flux increases two or three times. The tested membrane $\mathrm{B}$ belongs to the thicker cellulose membranes obtained in this experiment, with pore size of 2.19 $\pm 0.03 \mathrm{~nm}$ and a porosity of $22.6 \%$. The results obtained may indicate that the structure of membrane $B$ is compact, which prevents it from being crushed under water pressure.

Analyzing the transport properties of membrane $\mathrm{M}$, it can be observed that the specific permeate flux increases with the 
working pressure and is $1.25 \pm 0.08 \mathrm{~L} / \mathrm{m}^{2} \times \mathrm{h}$ (for $0.1 \mathrm{MPa}$ ), 6.22 $\pm 0.25 \mathrm{~L} / \mathrm{m}^{2} \times \mathrm{h}$ (for $0.15 \mathrm{MPa}$ ) and $10.19 \pm 0.46 \mathrm{~L} / \mathrm{m}^{2} \times \mathrm{h}$ (for $0.2 \mathrm{MPa}$ ). A high increase in the permeate flux, of five to eight times, indicates that the membrane is porous, but of a compact structure. Pore size calculations (Fig. 9) show that they are around $0.98 \pm 0.02 \mathrm{~nm}$, which is within the previously defined range of $0.608-2.371 \mathrm{~nm}$ [43]. All the obtained results indicate that the membrane $\mathrm{M}$ contains very small pores.

Very high volumetric permeate flux values are characteristic of membranes $\mathrm{H}$ and $\mathrm{O}$. For the cellulose membrane coagulated in 1-hexanol, the following values were recorded: $15.36 \pm 0.59$ $\mathrm{L} / \mathrm{m}^{2} \times \mathrm{h}$ (for a pressure of $0.1 \mathrm{MPa}$ ), $42.85 \pm 0.99 \mathrm{~L} / \mathrm{m}^{2} \times \mathrm{h}$ (for a pressure of $0.15 \mathrm{MPa}$ ) and $56.09 \pm 1.07 \mathrm{~L} / \mathrm{m}^{2} \times \mathrm{h}$ (for a pressure of $0.2 \mathrm{MPa}$ ). The obtained results are confirmed by the high porosity of membrane $\mathrm{H}$ (Fig. 7), observed in SEM images, which facilitates the transport of water through the membrane. The results of porosity calculations showed that the pore size (Fig. 9) in this membrane is $3.8 \pm 0.03 \mathrm{~nm}$, which is consistent with our previous results $(1.021 \pm 3.916 \mathrm{~nm})$, calculated from scattering curves [43]. Studies have shown that the membrane $\mathrm{H}$ is made of open pores. For membrane $\mathrm{O}$, the following results were obtained for transport properties: $12.72 \pm 0.45 \mathrm{~L} /$ $\mathrm{m}^{2} \times \mathrm{h}$ (for a pressure of $0.1 \mathrm{MPa}$ ), $65.70 \pm 2.15 \mathrm{~L} / \mathrm{m}^{2} \times \mathrm{h}$ (for a pressure of $0.15 \mathrm{MPa}$ ) and $92.19 \pm 1.51 \mathrm{~L} / \mathrm{m}^{2} \times \mathrm{h}$ (for a pressure of $0.2 \mathrm{MPa}$ ). These results show that during the operation of the cellulose membrane $O$, the permeate flux increases five to seven times with the increase of working pressure. The obtained results and the SEM images (Fig. 7) confirm that the cellulose membrane coagulated in 1-octanol is characterized by a large pore size of $3.61 \pm 0.03 \mathrm{~nm}$, which are responsible for very good transport properties.

The paper also attempts to investigate the separation properties of the obtained cellulose membranes. Literature reports that cellulose-based composite membranes have been used to remove metal ions such as $\mathrm{Fe}$ (III) and $\mathrm{Cu}$ (II) [47]. A $0.1 \mathrm{~g} / \mathrm{dm}^{3}$ aqueous solution of iron salt $\left(\mathrm{FeCl}_{3}\right)$ (Fig. 10) was selected to study the separation properties of cellulose membranes. During the study, a volumetric permeate flux and rejection coefficient were observed (Fig. 11). Studies have shown that the introduction of iron ion solution into cellulose membranes causes a rapid decrease in the permeate flux by approximately $67-96 \%$ already at the beginning of the process. The flow through the membrane is constantly decreasing during membrane operation and after about $60 \mathrm{~min}$, it is about 95$98 \%$. The obtained result may indicate that the introduction of iron ions into cellulose membranes results in fouling of all membranes obtained in the experiment. Detailed analysis of the obtained results showed that the highest volumetric permeate flux values during permeation of iron ions are demonstrated by membrane $\mathrm{O}$. Initially, the permeate flux is $4.75 \mathrm{~L} / \mathrm{m}^{2} \times \mathrm{h}$, and after $60 \mathrm{~min}$, it decreases to $2.93 \mathrm{~L} / \mathrm{m}^{2} \times \mathrm{h}$. For membrane $\mathrm{O}$ the decrease in flux is $94.85-96.82 \%$, at the beginning and the end of the process, respectively. At the same time, it is observed (Fig. 11) that the $\mathrm{FeCl}_{3}$ rejection coefficient is $61 \%$, so membrane $\mathrm{O}$ is not clogged completely. Such a result can confirm that it is very porous with large pores. Similar results were obtained for the study of transport properties of membrane $\mathrm{H}$ for which the volumetric permeate flux values were in the range of
2.28-1.14 L/m² $\times$ h (Fig. 10). The decrease in the permeate flux was $95.94-97.97 \%$ relative to that obtained for distilled water. $\mathrm{FeCl}_{3}$ rejection coefficient on membrane $\mathrm{H}$ was $62.32 \%$, which confirms the high porosity of this membrane. A similar result of the rejection coefficient of $61.31 \%$ was obtained for membrane W (Fig. 11). At the same time, it was observed that during the flow of iron (III) ions through membrane W, the decrease of the volumetric rejection coefficient at the beginning of the process was the lowest $(66.78 \%)$ and increased to $94.46 \%$ after $60 \mathrm{~min}$. The obtained results allow concluding that membranes $\mathrm{O}, \mathrm{H}$ and $\mathrm{W}$, characterized by low density and high porosity have similar separation properties relative to the aqueous solution of $\mathrm{FeCl}_{3}$.

For the remaining cellulose membranes $(M, E, P, B, P e)$, the decrease in the specific permeate flux for iron ions was similar and ranged between 95 and $98 \%$, with a rejection coefficient of $81.5 \%$ (for membrane B), 84 \% (for membrane Pe), $85.5 \%$ (for membrane $\mathrm{E}$ ), 86 \% (for membrane $\mathrm{M}$ ), $86.9 \%$ (for membrane $\mathrm{P})$. These membranes almost completely blocked iron (III) ions, while the permeate flux decreased to very low values of 0.15 $0.34 \mathrm{~L} / \mathrm{m}^{2} \times \mathrm{h}$. Membranes $\mathrm{M}, \mathrm{E}, \mathrm{P}, \mathrm{B}$ and $\mathrm{Pe}$ could be used to remove metals from solutions, as suggested in the work of Cifci et al. [47].

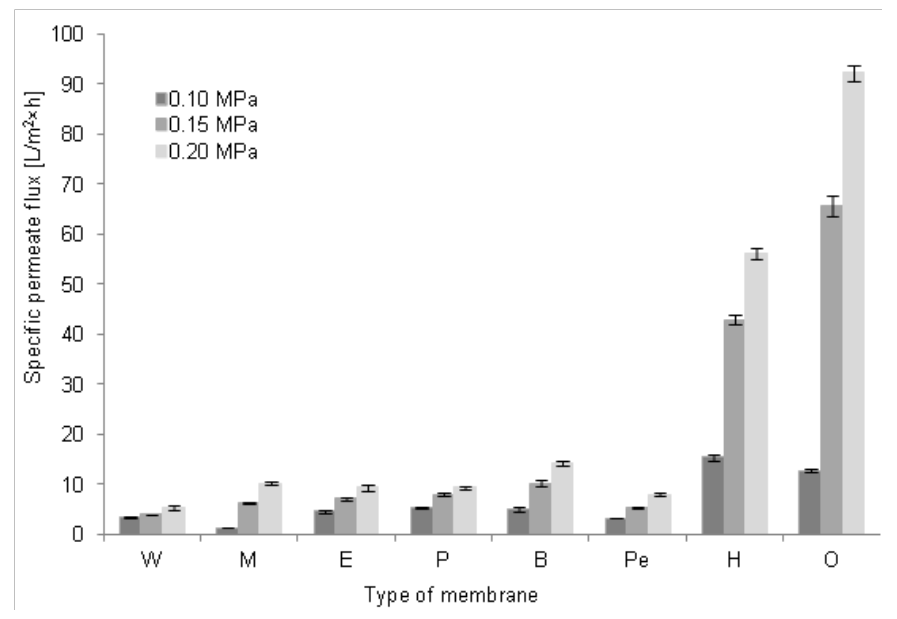

Figure 8. Water flux for the obtained cellulose membranes

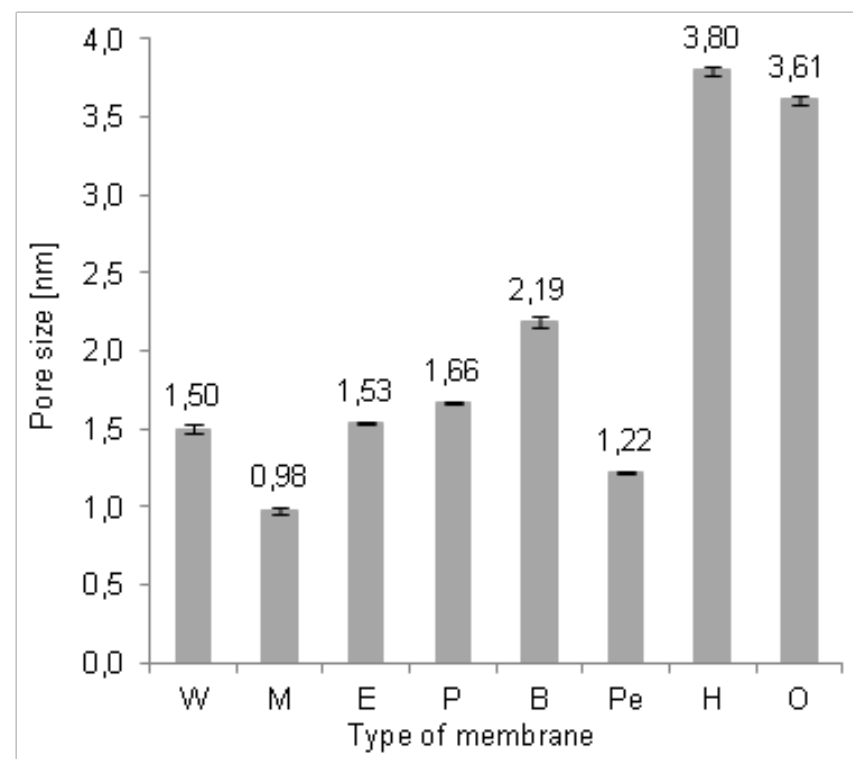

Figure 9. Pore sizes of the studied membranes 


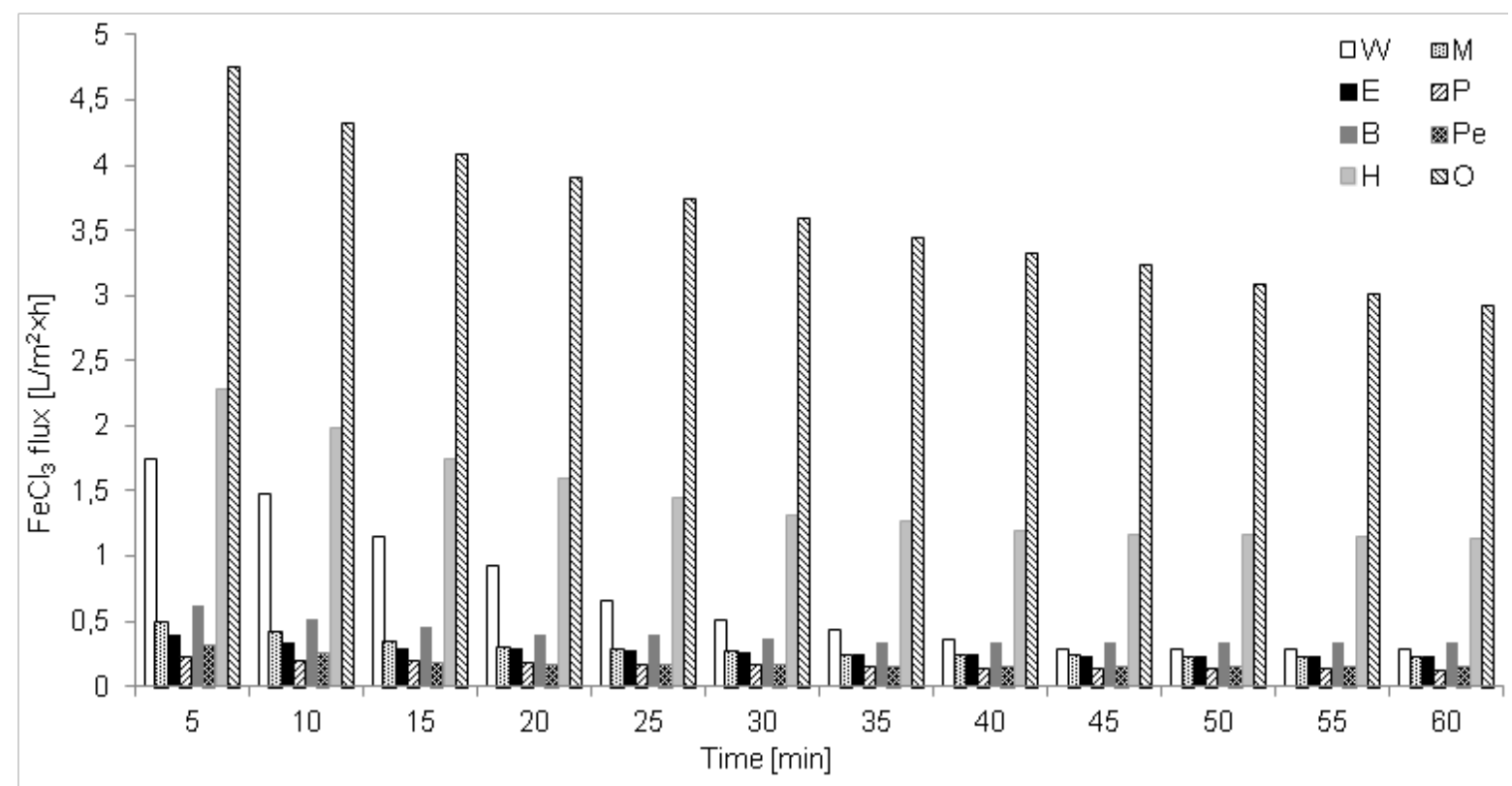

Figure 10. Volumetric permeate flux for the solution of $\mathrm{FeCl}_{3}$

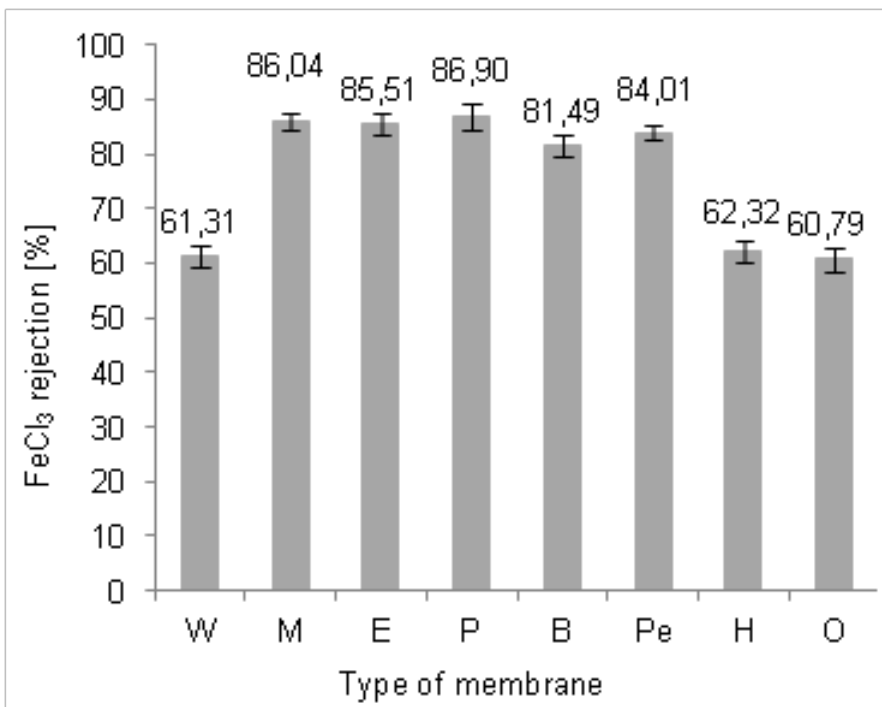

Figure 11. Rejection coefficient (R) for $\mathrm{FeCl}_{3}$ solution

\section{Conclusion}

This paper presents the results of research on the production of cellulose membranes from $5 \%$ cellulose solution in EMIMAc ionic liquid. The membranes were formed by phase inversion using water and primary alcohols, methanol, ethanol, 1-propanol, 1-butanol, 1-pentanol, 1-hexanol and 1-octanol, as coagulants. The analyzed physicochemical properties of cellulose membranes showed that membrane $M$ is the most compact of all obtained membranes, which can be deduced from SEM images, high density, pore size of $0.98 \mathrm{~nm}$, porosity around $60 \%$ and poor sorption properties. The resulting properties of membrane $\mathrm{M}$ are due to the coagulation process, which was carried out in methanol and proceeded very rapidly, rendering a thin membrane $(13 \mu \mathrm{m})$. Similar density values are characteristic of cellulose membrane $\mathrm{Pe}(0.9 \mathrm{~g} /$ $\mathrm{cm}^{3}$ ), which also has a low thickness, low sorption and a pore size of $1.22 \mathrm{~nm}$. It has been shown that during coagulation of membrane $\mathrm{Pe}$, which occurs very slowly, compact structures are formed, as observed in SEM images. Consequently, the transport properties are characterized by low values of volumetric permeate flux. The longest coagulation time was required to produce cellulose membranes $\mathrm{H}$ and $\mathrm{O}$, resulting in the thick membranes of the lowest density $(0.38-0.40 \mathrm{~g} /$ $\mathrm{cm}^{3}$ ), the highest pore sizes and porosity $99.8 \%$, sorption properties above $300 \%$ and very good transport properties. Therefore, coagulation of the cellulose solution in higher primary alcohols leads to very porous membrane structures that can be observed by scanning microscopy. For cellulose membrane $W$, low density $\left(0.47 \mathrm{~g} / \mathrm{cm}^{3}\right)$, thickness of $27 \mu \mathrm{m}$ and high porosity $(97 \%)$ were observed at the pore size of $1.5 \mathrm{~nm}$ and sorption of $19 \%$. These results indicate that the membrane $\mathrm{W}$ has a porous structure throughout its volume, which is confirmed in the cross-sectional images. The lowest values of volumetric permeate flux obtained in the experiment lead to the conclusion that cellulose membrane $\mathrm{W}$ is composed of closed pores, which hinder the flow of water. Other cellulose membranes: $\mathrm{E}, \mathrm{P}$ and $\mathrm{B}$, are characterized by similar densities $\left(0.62-0.69 \mathrm{~g} / \mathrm{cm}^{3}\right)$, low sorption (4-23\%), high porosity (87$97 \%$ ) and pore sizes within the range of $1.53-2.19 \mathrm{~nm}$. And the transport properties of the membranes at the working pressure of $0.2 \mathrm{MPa}$ were low, reaching $9.3 \mathrm{~L} / \mathrm{m}^{2} \times \mathrm{h}$ (membranes $\mathrm{E}$ and $\mathrm{P})$ and $14.2 \mathrm{~L} / \mathrm{m}^{2} \times \mathrm{h}$ (membrane $\left.\mathrm{B}\right)$, respectively.

Studies of the separation properties of cellulose membranes carried out using iron (III) solution showed that a very high decrease in flow of $67-96 \%$ and a high rejection coefficient (82-87\%) indicate a lack of resistance to unfavorable phenomena of fouling. Similar values of rejection coefficient observed experimentally for membrane $\mathrm{W}, \mathrm{H}$ and $\mathrm{O}$ (61-62 $\%$ ) may be related to their low density $\left(0.38-0.47 \mathrm{~g} / \mathrm{cm}^{3}\right)$. It can be concluded that the cellulose membranes obtained from the cellulose solution in EMIMAc as a result of coagulation in water and primary alcohols may be used for effective removal of trivalent iron ions.

FTIR spectra and WAXS curves confirm that during the regeneration of cellulose there is a change in the macromolecular structure that results in a large number of amorphous regions. 


\section{ACKNOWLEDGEMENTS}

The presented research was carried out within the framework of the key project entitled "Biodegradable fibrous products"(acronym: Biogratex) supported by the European Regional Development Fund; Agreement No. POIG.01.03.01-00-007/08-00.

\section{References}

[1] Klemm, D., Heublein, B., Fink, H.P., Bohn, A. (2005). Cellulose: Fascinating biopolymer and sustainable raw material. Angewandte Chemie - Inernational Edition, 44, 3358-3393.

[2] Fink, H.P., Weigel, P., Purz, H.J., Ganster, J. (2001). Structure formation of regenerated cellulose materials from NMMO-solutions. Progres in Polymer Science, 26, 1473-1524.

[3] Edgar, K.J., Buchanan, C.M., Debenham, J.S., Rundquist, P.A., Seiler, B.D., Shelton, M.C., Tindall, D. (2001). Advances in cellulose ester performance and application. Progres in Polymer Science, 26, 1605-1688.

[4] Jin, H., Zha, C., Gu, L. (2007). Direct dissolution of cellulose in $\mathrm{NaOH} /$ thiourea/urea aqueous solution. Carbohydrate Research, 342, 851-858.

[5] Cao, Y., Zhang, R., Cheng, T., Guo, J., Xian, M., Liu, H. (2017). Imidazolium-based ionic liquids for cellulose pretreatment: recent progresses and future perspectives. Applied Microbiology and Biotechnology, 101, 521-532.

[6] Singh, P., Duarte, H., Alves, L., Antures, F., Le Moigne, N., Dormanns, J., Duchemin, B., Staiger, M. P. (2015., Cellulose - Fundamental Aspects and Current Trends. Cellulose - Fundamental Aspects and Current Trends, 237-261.

[7] Pinkert, A., Marsh, K.N., Pang, S., Staiger, M.P. (2009). lonic liquids and their interaction with cellulose. Chemical Reviews, 109, 6712-6728.

[8] Fukaya, Y., Hayashi, K., Wada, M., Ohno, H. (2008). Cellulose dissolution with polar ionic liquids under mild conditions: required factors for anions. Green Chemistry, 10(1), 44-46.

[9] Laus, G., Bentivoglio, G., Schottenberger, H., Kahlenberg, V., Kopacka, H., Roeder, T., Sixta, H. (2005). Ionic Liquids: Current Dev Elopments, Potential and Drawbacks for Industr lal Applications. Lenzinger Berichte, 84, 71-85.

[10] Hermanutz, F., Gähr, F., Uerdingen, E., Meister, F., Kosan, $B$. (2008). New developments in dissolving and processing of cellulose in ionic liquids, Macromolecular Symposia, 262, 23-27.

[11] Cao, Y., Wu, J., Zhang, J., Li, H., Zhang, Y., He, J. (2009). Room temperature ionic liquids (RTILs): A new and versatile platform for cellulose processing and derivatization. Chemical Engineering.Journal, 147, 13-21.

[12] Spörl, J.M., Ota, A., Son, S., Massonne, K., Hermanutz, F., Buchmeiser, M.R. (2016). Carbon fibers prepared from ionic liquid-derived cellulose precursors. Materials Today Commuications, 7, 1-10.

[13] Sundberg, J., Guccini, V., Håkansson, K.M.O., SalazarAlvarez, G., Toriz, G., Gatenholm, P. (2015). Controlled molecular reorientation enables strong cellulose fibers regenerated from ionic liquid solutions. Polymer (United Kingdom), 75, 119-124.
[14] Sun, L., Chen, J.Y., Jiang, W., Lynch, V. (2015). Crystalline characteristics of cellulose fiber and film regenerated from ionic liquid solution. Carbohydate Polymers, 118, 150-155.

[15] Bulota, M., Michud, A., Hummel, M., Hughes, M., Sixta, $H$. (2016). The effect of hydration on the micromechanics of regenerated cellulose fibres from ionic liquid solutions of varying draw ratios. Carbohydrate Polymers, 151, 11101114.

[16]Xu, J., Hou, H., Liu, B., Hu, J. (2017). The integration of different pretreatments and ionic liquid processing of eucalyptus: Hemicellulosic products and regenerated cellulose fibers. Industrial Crops and Products, 101, 1120.

[17] Kosan, B., Michels, C., Meister, F. (2008). Dissolution and forming of cellulose with ionic liquids. Cellulose., 15, 5966.

[18] Michud, A., Hummel, M., Sixta, H. (2015). Influence of molar mass distribution on the final properties of fibers regenerated from cellulose dissolved in ionic liquid by dryjet wet spinning. Polymer (United Kingdom), 75, 1-9.

[19] Wanasekara, N.D., Michud, A., Zhu, C., Rahatekar, S., Sixta H., Eichhorn S.J. (2016). Deformation mechanisms in ionic liquid spun cellulose fibers. Polymer (United Kingdom), 99, 222-230.

[20] Suzuki, T., Kono, K., Shimomura, K., Minami, H. (2014). Preparation of cellulose particles using an ionic liquid. Journal of Colloid and Interface Science, 418, 126-131.

[21] Kimura, A., Nagasawa, N., Taguchi, M. (2014). Cellulose gels produced in room temperature ionic liquids by ionizing radiation. Radiation Physics and Chemistry, 103, 216-221.

[22] Oshima, T., Sakamoto, T., Ohe, K., Baba, Y. (2014). Cellulose aerogel regenerated from ionic liquid solution for immobilized metal affinity adsorption. Carbohydrate Polymers, 103, 62-69.

[23] Liao, H., Zhang, H., Hong, H., Li, Z., Qin, G., Zhu, H., Lin, Y. (2016). Novel cellulose aerogel coated on polypropylene separators as gel polymer electrolyte with high ionic conductivity for lithium-ion batteries. Journal of Membran Science, 514, 332-339.

[24] Östlund, A., Idström, A., Olsson, C., Larsson, P.T., Nordstierna, L. (2013). Modification of crystallinity and pore size distribution in coagulated cellulose films. Cellulose, 20, 1657-1667.

[25] Ding, Z.D., Chi, Z., Gu, W.X., Gu, S.M., Liu, J.H., Wang, H.J. (2012). Theoretical and experimental investigation on dissolution and regeneration of cellulose in ionic liquid. Carbohydrate Polymers, 89, 7-16.

[26] Swatloski, R.P., Spear, S.K., Holbrey, J.D., Rogers, R.D. (2002). Dissolution of cellulose with ionic liquids. Journal of American Chemical Society, 124, 4974-4975.

[27] Wendler, F., Todi, L.N., Meister, F. (2012). Thermostability of imidazolium ionic liquids as direct solvents for cellulose. Thermochimica Acta, 528, 76-84.

[28] Mahadeva, S.K., Kim, J. (2012). Influence of residual ionic liquid on the thermal stability and electromechanical behavior of cellulose regenerated from 1-ethyl-3methylimidazolium acetate. Fibers and Polymers, 13(3), 289-294.

[29] Sun, N., Rahman, M., Qin, Y., Maxim, M.L., Rodríguez, H., Rogers, R.D. (2009). Complete dissolution and partial delignification of wood in the ionic liquid 1-ethyl-3methylimidazolium acetate. Green Chemistry, 11, 646. 
[30] Livazovic, S., Li, Z., Behzad, A.R., Peinemann, K.-V., Nunes, S.P. (2015). Cellulose multilayer membranes manufacture with ionic liquid. Journal of. Membran Science, 490, 282-293.

[31] Li, X.L., Zhu, L.P., Zhu, B.K., Xu, Y.Y. (2011). High-flux and anti-fouling cellulose nanofiltration membranes prepared via phase inversion with ionic liquid as solvent. Separation and Purification Technology, 83, 66-73.

[32] Turner, M.B., Spear, S.K., Holbrey, J.D., Daly, D.T., Rogers, R.D. (2005). Ionic liquid-reconstituted cellulose composites as solid support matrices for biocatalyst immobilization. Biomacromolecules, 6, 2497-2502.

[33] Gupta, K.M., Hu, Z., Jiang, J. (2011). Mechanistic understanding of interactions between cellulose and ionic liquids: A molecular simulation study. Polymer (Guildf), 52. 5904-5911.

[34] Feng, L., lan Chen, Z. (2008). Research progress on dissolution and functional modification of cellulose in ionic liquids. Journal of Molecular Liquids, 142, 1-5.

[35] Tan, H.T., Lee, K.T., Mohamed, A.R. (2011). Pretreatment of lignocellulosic palm biomass using a solvent-ionic liquid [BMIM]Cl for glucose recovery: An optimisation study using response surface methodology. Carbohydrate Polymers, 83, 1862-1868.

[36] Xiao, W., Yin, W., Xia, S., Ma, P. (2012). The study of factors affecting the enzymatic hydrolysis of cellulose after ionic liquid pretreatment. Carbohydrate Polymers, 87, 2019-2023.

[37] Zinadini, S., Zinatizadeh, A.A., Rahimi, M., Vatanpour, V., Zangeneh, H. (2014). Preparation of a novel antifouling mixed matrix PES membrane by embedding graphene oxide nanoplates. Journal of Membran Science, 453, 292301.

[38] Wypych, G. (2012). Handbook of Polymers (2nd edition). ChemTec Publishing (Ontario, Canada).

[39] Marrinan H.J., Mann J. (1956). Infrared spectra of the crystalline modifications of cellulose. Journal of Polym. Science, 21, 301-311.

[40] Jung H.Z., Benerito R.R., Berni R.J., Mitcham D. (1977). Effect of low temperatures on polymorphic structures of cotton cellulose. Journal of Applied Polymer Science, 21, 1981-1988.

[41] Akira, I. (2001). Material Science of Cellulose. Tokyo University Press (Tokyo).

[42] Rabiej, M. (2017). Application of the particle swarm optimizationmethod for the analysis of wide-angle $X$-raydiffraction curves of semicrystalline polymers. Journal of Applied Crystallography, 50, 221-230.

[43] Ślusarczyk, C., Fryczkowska, B., Sieradzka, M., Janicki, J. (2016). Small-angle $X$-ray scattering studies of pore structure in cellulose membranes. Acta Physica Polonica A, 229-232.

[44] Zhang, H., Wu, J., Zhang, J., He, J. (2005). 1-allyl-3methylimidazolium chloride room temperature ionic liquid: A new and powerful nonderivatizing solvent for cellulose. Macromolecules, 38, 8272-8277.

[45]Xu, A., Guo, X., Xu, R. (2015). Understanding the dissolution of cellulose in 1-butyl-3-methylimidazolium acetate $+D M A c$ solvent. International Journal of Biological Macromolecules, 81, 1000-1004.

[46] Mahadeva, S.K., Kim, J. (2012). Influence of residual ionic liquid on the thermal stability and electromechanical behavior of cellulose regenerated from 1-ethyl-3methylimidazolium acetate. Fibers and Polymers, 13, 289294.

[47] Çifci, C., Kaya, A. (2010). Preparation of poly(vinyl alcohol)/ cellulose composite membranes for metal removal from aqueous solutions. Desalination, 253, 175-179. 